\title{
USO DE FILTROS ORGÂNICOS NA REMOÇÃO DE ÓLEOS E GRAXAS PRESENTES NA ÁGUA RESIDUÁRIA DE SUINOCULTURA
}

\author{
Marcos Alves Magalhães ${ }^{1}$, Paola Alfonsa Vieira Lo Monaco², AntonioTeixeira de Matos ${ }^{3}$
}

\section{RESUMO}

Objetivou-se, com a realização deste trabalho, avaliar a eficiência de filtros orgânicos na remoção de óleos e graxas presentes em água residuária de suinocultura (ARS). Como materiais filtrantes, foram utilizados o bagaço de canade-açúcar triturado, a serragem de madeira e o pergaminho de grãos de café. Tonéis metálicos de 1,30 m de altura e $0,58 \mathrm{~m}$ de diâmetro foram preenchidos com os respectivos resíduos orgânicos e, em seguida, submetidos à aplicação de ARS em escoamento descendente até que a taxa de filtração passasse a ser menor que $0,2 \mathrm{~L} \mathrm{~m}^{-2} \mathrm{~s}^{-1}$. Amostras de ARS, antes e após a filtração, foram coletadas afim de se avaliar a concentração de óleos e graxas presentes na água residuária. De acordo com os resultados obtidos, os filtros orgânicos mostraram-se promissores na remoção de óleos e graxas presentes na água residuária de suinocultura, alcançando valores de 97,2; 88,9 e 82,3\% utilizando-se o bagaço de cana-de-açúcar triturado, serragem de madeira e pergaminho de grãos de café, respectivamente.Os filtros não foram eficientes o suficiente para atender a Resolução CONAMA n ${ }^{\circ} 430 / 2011$, referentes ao atendimento quanto ao padrão de lançamento dos efluentes para óleos e graxas, no entanto, permitiram melhoria considerável na qualidade do efluente.

Palavras-chave:filtração, resíduos orgânicos, óleos e graxas

\section{ABSTRACT \\ USE OF ORGANIC FILTERS IN THE REMOVAL OF OILS AND FATS PRESENTS IN SWINE WASTEWATER}

The aim of this study was to evaluate the efficiency of organic filters for removing oils and fats present in swine wastewater (SW). Crushed sugar cane, sawdust and parchment of coffee beans were used as filter materials. Metallic barrels measuring $1.30 \mathrm{~m}$ tall and $0.58 \mathrm{~m}$ in diameter were filled with the respective organic residues and then submitted to application of SW until the filtration rate became less than $0.2 \mathrm{~L} \mathrm{~m}^{-2} \mathrm{~s}^{-1}$. SW samples were collected before and after filtration in order to evaluate the concentration of oil and fats present in the wastewater. According to the results, the organic filters showed promise for removing oils and fats present in swine wastewater, reaching values of 97.2, 88.9 and $82.3 \%$ for crushed sugarcane bagasse, sawdust and parchment of coffee beans, respectively. The filters were not sufficiently efficient to meet the CONAMA Resolution $\mathrm{n}^{\circ} 430 / 2011$ referring to the standards for release oil and fat effluents, however they permitted for a considerable improvement in effluent quality.

Keywords: filtration, organic wastes, oils and fats

Recebido para publicação em 30/10/2012. Aprovado em 26/02/2013.

1 - Eng ${ }^{\circ}$ Agrônomo, D.S em Eng ${ }^{a}$ Agrícola, Professor da UNEC, Caratinga - MG, marcos@ufv.br .

2 - Eng ${ }^{\circ}$ Agrícola, D. S em Eng ${ }^{a}$ Agrícola, Professora da IFES, Santa Maria de Jetibá - ES, paolalm@ifes.edu.br

3 - Eng ${ }^{\circ}$ Agrícola, D.S em Solos e Nutrição de plantas, Professor do Depto. de Enga Agr da UFV, Viçosa - MG, atmatos@ufv.br . 


\section{INTRODUÇÃO}

A maior parte da matéria sólida presente em águas residuárias da suinocultura (ARS) é de natureza orgânica e, dentre os vários constituintes, apresentam grande quantidade de óleos e graxas, originados dos óleos da gordura animal e dos óleos vegetais presentes nas rações.

As águas residuárias ricas em óleos e graxas causam graves impactos ambientais quando lançadas diretamente em corpos hídricos receptores. Dentre os principais, destaca-se a formação do filme sobre a superfície, dificultando as trocas gasosas entre a atmosfera e o meio líquido, e o aumento da DQO e DBO, em razão da decomposição química e bioquímicados componentes orgânicos dos óleos e graxas. Bertiet al. (2009) afirmaram que os óleos e graxas presentes em águas residuárias descartadas, ao alcançarem córregos ou rios, tendem a ser absorvidos pelos vegetais aquáticos como também pelos que habitam as margens, interagindo com os sedimentos, podendo afetar os organismos que ali vivem ou que se alimentam destes sedimentos e vegetais.

Em razão da grande quantidade de nutrientes presentes nas ARS, bem como a necessidade de dispô-la de forma adequada no meio ambiente, a fertirrigação com essas águas residuárias vem sendo cada vez mais utilizada. No entanto, vários são os inconvenientes decorrentes da presença de óleos e graxas em águas residuárias de suinocultura quando aplicadas à sistemas de irrigação localizada. Dentre os principais problemas pode-se citar a aderência às paredes de tubulações, bombas, válvulase demais equipamentos acessórios; aderência às paredes de tanques e unidades de tratamento; obstruções nas canalizações, peças e equipamentos e, com a decomposição do material orgânico há a emanação de maus odores. Quando disposta diretamente no solo, sem a devida préremoção de gorduras, pode ocorrer colmatação dos poros das camadas superficiais do solo, causando dificuldades à infiltração de água e a troca de gases entre a atmosfera e o solo, apodrecimento de raízes, geração de maus odores e, com isso, atração de insetos e outros vetores de doenças.

Dessa forma, quer sejam lançadas em corpos hídricos receptores, quer sejam aplicadas visandose seu aproveitamento agrícola, a ARS deve passar por um tratamento primário para a remoção dos óleos e graxas.

Dentre os processos de tratamentos mais utilizados para a remoção de óleos e graxas destacam-se os separadores gravitacionais, separadores de grade, filtração, adsorção e o processo de flotação com ar dissolvido (FAD), no caso de remoção de partículas oleosas mais finas. No entanto, formas de tratamentos mais simples e de baixo custo tornam-se necessárias quando se trata de pequenas comunidades rurais. A utilização de filtros de areia pode ser uma forma de tratamento de baixo custo, no entanto, envolve outra problemática que é o destino final desse material impregnado de óleo, cujo descarte de forma imprópria tende a se transformar em passivo ambiental.

Dentre as possíveis formas de tratamento para remoção de óleos e graxas de águas residuárias em pequenas comunidades, destaca-se a utilização de filtros constituídos por resíduos orgânicos. Tais resíduos, oriundos de atividades agrícolas, podem ser boa opção para utilização como meio filtrante, devido à sua abundância, baixo custo de aquisição e, ainda, em razão da possibilidade de serem submetidos à compostagem após serem descartados dos filtros e, posteriormente, utilizados como fertilizante agrícola. Por essa razão, alguns resíduos utilizados como filtros orgânicos têm sido avaliados, tais como bagaço de cana-de-açúcar (LO MONACO et al., 2011a, MAGALHÃES et al., 2006; MATOS et al., 2010); serragem de madeira (LO MONACO et al., 2004; MAGALHÃES et al., 2005; MAGALHÃES et al., 2006; MATOS et al., 2010), casca de arroz (BRANDÃO et al., 2003), sabugo de milho triturado (BRANDÃO et al., 2003; LO MONACO et al., 2011a), fino de carvão (BRANDÃO et al., 2003), casca de frutos do cafeeiro (BRANDÃO et al., 2003), fibra de coco (LO MONACO et al., 2009), além de pergaminho de grãos de café (MATOS et al., 2006; LO MONACO et al., 2011b; MATOS et al., 2010), tendo apresentado bons resultados na remoção de diversos poluentesde águas residuárias diversas.

Além do poder filtrante desses resíduos, atuando como processo físico de remoção, diversos trabalhos vêm mostrando que biomassas em geral, tais como o mesocarpo do coco (SANTOS et al., 2007), o bagaço de cana-de-açúcar (SANTOS et al., 2007; SILVA, et al., 2007; SOUZA et al.,

\section{REVENG}

387-395p. Engenharia NA Agricultura, VIÇOSA - MG, V.21 N.4, JUlHo / AgOSto 2013 
2011) e a serragem de madeira (SANTOS et al., 2007), apresentam elevada capacidade de adsorção de contaminantes de derivados do petróleo, como o óleo díesel. De acordo com Rubio et al. (2003), a propriedade altamente hidrofóbica de biomassas, somada à elevada porosidade, possibilita a adsorção de óleos por capilaridade. Tecidos vegetais, com alta área superficial e com grandes poros, adsorvem contaminantes orgânicos por mecanismos físicoquímicos, de maneira semelhante a que se obtém quando se utiliza carvão ativado. Schmidt (2010) afirmou que a tensão interfacial e a molhabilidade do fluido são propriedades de grande importância na retenção de substâncias não miscíveis em água, quando em escoamento em meios porosos. $\mathrm{O}$ autor define tensão interfacial como a energia desenvolvida no contato entre líquidos, líquido e gás ou líquido e sólido, e que está associada com o nível de atração entre as moléculas em contato. A molhabilidade, por sua vez, refere-se ao espalhamento preferencial de um fluido em relação ao outro nas superfícies sólidas, estando relacionada à tensão interfacial, tendo em vista estar associada ao ângulo de contato formado na interface com o sólido. $\mathrm{O}$ ângulo de contato também está associado ao efeito capilar.

Em razão da escassez de informações a respeito da remoção de óleos e graxas por filtros orgânicos, objetivou-se, com a realização deste trabalho, avaliar o uso de filtros orgânicos de bagaço de cana-de-açúcar, serragem de madeira e pergaminho de grãos de café para remoção de óleos e graxas presentes na água residuária da suinocultura.

\section{MATERIAL E METÓDOS}

A serragem de madeira, o bagaço de canade-açúcar e o pergaminho dos grãos decafé, por serem subprodutos abundantes de atividades agropecuárias e industriais, de baixo custo, de fácil aquisição e por serem capazes de absorver e adsorver solutos e reter sólidos em suspensão foram utilizados no preenchimento das colunas de filtração.

Para triturar a serragem de madeira e o bagaço de cana-de-açúcar foi utilizado o equipamento Desintegrador/Picador/Moedor (DPM), $\mathrm{n}^{\mathrm{o}} \quad 01$, constituído de 4 conjuntos de 3 martelos (total de 12 martelos), peneira com malha de $10 \mathrm{~mm}$ e motor de 5 cv. Depoisde triturado, os materiais orgânicos foram peneirados em diferentes malhas, de forma a se obter duas faixas granulométricas: 2,0 a3,0 e 5,0 a $8,0 \mathrm{~mm}$.

A escolha das faixas granulométricas para o material filtrante foi baseada nos resultados obtidos por Lo Monaco et al. (2004), que recomendaram o uso de granulometrias entre 2,0 e $3,0 \mathrm{~mm}$, por serem as que proporcionaram filtração mais eficiente sem, contudo, aumentar em demasia a perda de carga no sistema filtrante. A faixa granulométrica de 5,0 a $8,0 \mathrm{~mm}$ foi usada para constituir a camada superficial do filtro, para evitar que ocorresse rápida colmatação na superfície do material filtrante e, com isso, decréscimo muito rápido na taxa de filtração da água residuária.

Após a preparação dos materiais orgânicos (secagem ao ar livre, trituração e peneiramento para se obter materiais na faixa granulométrica entre 2,0 e 3,0 mm), amostras desses materiais foram recolhidas e utilizadas para que se pudesse quantificar o volume de poros e, assim, se determinar a porosidade do meio filtrante. Para isso, amostras de bagaço de cana-de-açúcar, serragem de madeira e pergaminho dos grãos decafé foram colocados em recipientes de formatos cilíndricos, de volume conhecido (1000 mL), tendo-se ocuidado de efetuar o mesmo procedimento utilizado quando da montagem dos filtros, isto é, submeter os materiais filtrantes à mesma compressão de $16,7 \mathrm{kN} \mathrm{m}^{-2}$. Após esses recipientes estarem completamente ocupados pelas amostras, foi aplicado sobre estas, o tolueno, líquido indicado para se avaliar porosidade, por ser uma solução de baixa tensão superficial, sendo esta uma característica que lhe permite alta eficiência para ocupar os espaços vazios do material. Com o auxílio de uma pipeta, o tolueno foi aplicado sobre o material contido no recipiente, até que o volume total do recipiente fosse completado. $\mathrm{O}$ volume de tolueno usado no preenchimento do volume de poros do material orgânico foi considerado no cálculo da porosidade. O procedimento foi repetido por três vezes.

No Quadro 1 estão apresentados os valores de porosidade para os diferentes resíduos orgânicos utilizados como materiais filtrantes. 
Quadro1. Valores de porosidade para os diferentes resíduos orgânicos utilizados como materiais filtrantes.

\begin{tabular}{lc}
\hline Material filtrante & Porosidade $\left(\mathrm{cm}^{3} \mathrm{~cm}^{-3}\right)$ \\
\hline Serragem de madeira & 0,849 \\
Bagaço de cana-de-açúcar & 0,805 \\
Pergaminhos de grãos de café & 0,881 \\
\hline
\end{tabular}

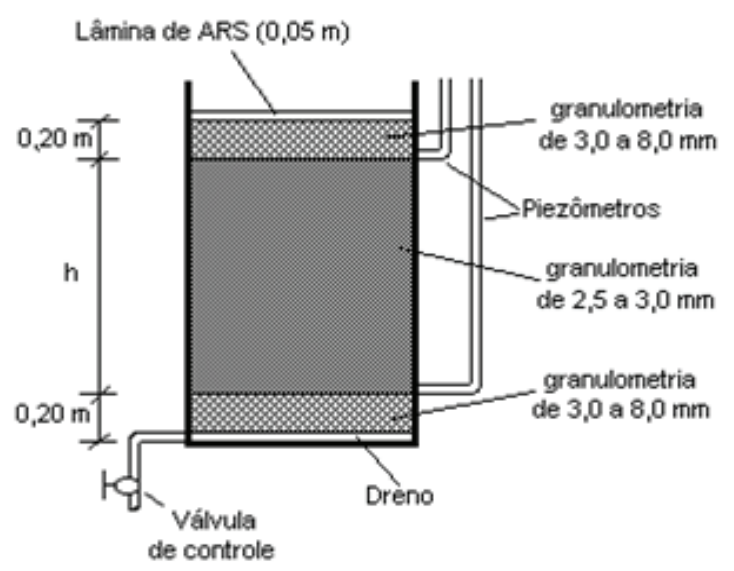

Figura 1. Esquema de montagem do filtro orgânico não segmentado.

O sistema de filtração instalado, operado e monitorado na Área Experimental de Hidráulica/ Irrigação e Drenagem do Departamento de Engenharia Agrícola da Universidade Federal de Viçosa, foi constituído por recipientes metálicos (tonéis) como colunas filtrantes, com as seguintes dimensões: $0,58 \mathrm{~m}$ de diâmetro por 1,30 $\mathrm{m}$ altura.

Os materiais orgânicos (bagaço de cana-deaçúcar, serragem de madeira e pergaminho de grãos de café) foram triturados e peneirados e, em seguida, acondicionados nas colunas filtrantes não segmentadas, de forma gradual, em camadas de aproximadamente $10 \mathrm{~cm}$, até ser alcançada a altura total de $1,30 \mathrm{~m}$.

As colunas de filtração foram montadas da seguinte forma: no fundo de cada recipiente foi instalado um sistema de drenagem, por onde foi coletado o efluente filtrado, constituído por tubos de PVC de $50 \mathrm{~mm}$ de diâmetro, perfurados (furos com $\varnothing=2,0 \mathrm{~mm}$ ). Os furos efetuados no tubo de PVC eram espaçados a cada $0,10 \mathrm{~m}$ entre si, totalizando 8 furos. Para evitar a passagem de partículas do material filtrantee entupimento dos drenos, uma camada (h1) de 0,20 m, constituída de material grosseiro (partículas do mesmo material orgânico, nos diâmetros de 3,0 - 8,0 mm), foi disposta no fundo dos recipientes, cobrindo o dreno; sobre a camada de material mais grosseiro (h1), foi disposta uma camada de material filtrante com $0,90 \mathrm{~m}$ de altura (h2) e com granulometria de 2,5 a $3,0 \mathrm{~mm}$, conforme esquema apresentado na Figura 1.

Para evitar que ocorresse a rápida colmatação da camada superficial do filtro, foi disposta, sobre a coluna filtrante, uma camada de $0,20 \mathrm{~m}$ de altura (h3), constituída de material de mesma granulometria do material que foi colocado junto aos drenos (3,0 -8,0 mm).

Após a disposição de cada camada de resíduo na coluna, foi feita a compactação do material com uma prensa, sob compressão de $16,7 \mathrm{kN} \mathrm{m}^{-2}$, equivalente à pressão exercida por um homem com massa de $50 \mathrm{~kg}$, apoiado em um só pé. Para minimizar o escoamento preferencial na parede interna da coluna, o material de preenchimento foi comprimido com as pontas dos dedos em toda a periferia do filtro, durante a fase de enchimento dos mesmos.

Após a compactação do material filtrante acondicionado na coluna de filtração, foi aplicada lâmina da ARS, de escoamento descendente, para que este operasse na condição saturada, durante todo o tempo.

A água residuária utilizada no experimento foi coletada em tanque de concreto de $5 \mathrm{~m} \times 3 \mathrm{~m} \times 3$ $\mathrm{m}$, onde são estocados os efluentes gerados nas

\section{REVENG


instalações da suinocultura da UFV, e conduzida ao tanque de distribuição, de onde foi transferida, por gravidade, aos filtros.

A ARS coletada passou, previamente, por um processo de pré-filtragem através de uma tela com malha de $0,635 \mathrm{~mm}$ de diâmetro (40 mesh), com o objetivo de reter os materiais mais grosseiros que poderiam comprometer, rapidamente, $\mathrm{o}$ desempenho dos filtros orgânicos. A tela foi fixada numa estrutura de madeira, cujo conjunto foi instalado sobre o tanque, sendo instalado com uma inclinação de, aproximadamente, $45^{\circ}$ e operou de forma estática, com limpeza automática, por gravidade.

$\mathrm{Na}$ tubulação que conduziu a água residuária até a coluna de filtração foi instalada uma válvula para permitir controle da vazão de alimentação do sistema. Antes dos filtros serem operados, tomou-se o cuidado de eliminar o ar presente no espaço poroso do material filtrante. A eliminação do ar foi feita mediante o enchimento da coluna filtrante, vagarosamente com ARS, para permitir a eliminação do ar dosespaços porosos. Durante esse enchimento, a válvula de controle instalada na base do filtro foi mantida fechada, até o enchimento total do filtro com a ARS. Em seguida,iniciada a aplicação da ARS, a válvula de saída do efluente foi aberta para dar vazão ao líquido, permitindo o movimento do líquido nos interstícios do material filtrante, sendo as colunas mantidas saturadas, na condição de filtro lento. Durante todo o período de filtração, procurou-se manter uma lâmina permanente de $5,0 \mathrm{~cm}$ da ARS sobre asuperfície do filtro, por meio de controle nas válvulas, o que constituiu a carga hidrostática sobre o material filtrante.

No período de operação dos filtros, as águas residuárias armazenadas na caixa dedistribuição foram sistematicamente revolvidas para que não houvesse sedimentação domaterial no fundo do recipiente.

O período de operação dos filtros não segmentados foi condicionado à observação dos valores de perda de carga da coluna filtrante. Monitorando a perda de carga por meio de leituras feitas nos piezômetros, a operação dos filtros foi encerrada no momento em que aperda de carga aumentou, de tal forma a proporcionar taxa de filtração menor que $0,2 \mathrm{~L} \mathrm{~m}^{-2} \mathrm{~s}^{-1}$, observando-se, a partir daí, filtração da ARS demasiadamente lenta. Uma vez suplantada a capacidade dos filtros em reter poluentes, os materiais utilizados como meio filtrante foram removidos das colunas e descartados para tratamento pelo processo de compostagem.

Para determinação de óleos e graxas presentes na ARS, amostras do afluente e do efluente foram coletadas e analisadas de acordo com Standard Methods... (APHA et al., 2005), cujo método de quantificação utiliza o equipamento Extrator Soxhlet (condensador). A determinação analítica de óleos e graxas foi baseada na sua extração com um solvente volátil, sendo utilizado o solvente orgânico n-hexano (éter de petróleo).

$\mathrm{Na}$ avaliação das concentrações, o experimento foi montado no delineamento inteiramente casualizado, tendo quatro tratamentos (T0 - água bruta, T1 - filtração com serragem de madeira, T2 - filtração com bagaço de cana-de-açúcar e T3 - filtração com pergaminho de frutos do cafeeiro) e três repetições. Os resultados obtidos foram submetidos à análise de variância e, posteriormente, ao teste de Tukey, em nível de 5\% de probabilidade. Para avaliação da eficiência de filtração dos materiais filtrantes, o experimento foi analisado no delineamento inteiramente casualizado, porém, tendo três tratamentos (T1 - serragem de madeira, T2 - bagaço de cana-de-açúcar e T3 - pergaminho dos frutos do cafeeiro) e três repetições. Os resultados obtidos foram submetidos à análise de variância e, posteriormente, ao teste de Tukey, em nível de $5 \%$ de probabilidade.

\section{RESULTADOS E DISCUSSÃO}

No Quadro 2 estão apresentadas as concentrações médias de óleos e graxas da ARS afluente e efluente dos diferentes filtros orgânicos e, no Quadro 3, as eficiências médias obtidas na remoção de óleos e graxas.

De acordo com os resultados apresentados no Quadro 2, observa-se que as concentrações de óleos e graxas no efluente de todos os resíduos orgânicos diferiram das do afluente, indicando efeito do tratamento de filtração. Os baixos valores de concentração efluente são indicativos de que os resíduos estudados promovem a retenção óleos e graxas da ARS. 
Quadro 2. Concentrações médias de óleos e graxas na ARS afluente e efluente dos diferentes filtros orgânicos.

\begin{tabular}{lc}
\hline Tratamentos & Concentrações médias $\left(\mathbf{g ~ L}^{-1}\right)$ \\
\hline T0 - Testemunha & $2,850 \mathrm{a}$ \\
T3 - Pergaminho de grãos de café & $0,620 \mathrm{~b}$ \\
T1 - Serragem de madeira & $0,389 \mathrm{~b}$ \\
T2 - Bagaço de cana-de-açúcar & $0,099 \mathrm{~b}$ \\
\hline
\end{tabular}

*Médias seguidas pela mesma letra não diferem entre si, pelo teste de Tukey, em nível de $5 \%$ de probabilidade.

Quadro3. Eficiências médias de remoção de óleos e graxas da ARS pelos diferentes materiais filtrantes

\begin{tabular}{lc}
\hline Tratamento & Eficiência de remoção (\%) \\
\hline T2 - Bagaço de cana-de-açúcar & $97,2 \mathrm{a}$ \\
T1 - Serragem de madeira & $88,9 \mathrm{~b}$ \\
T3 - Pergaminho de grãos de café & $82,3 \mathrm{c}$ \\
\hline
\end{tabular}

*Médias seguidas pela mesma letra não diferem entre si, pelo teste de Tukey, ao nível de 5\% de probabilidade.

No Quadro 3, onde estão apresentados os resultados da eficiência média de remoção dos materiais filtrantes, observa-se que os materiais filtrantes apresentaram eficiências diferentes entre si, tendo o bagaço de cana-de-açúcar picado apresentado a maior eficiência, seguido da serragem de madeira e, por último, o pergaminho de grãos de café.

Pereiraet al. (2011), ao avaliarem a eficiência de remoção de diversas variáveis em sistema de tratamento de ARS composto por caixa de retenção de sólidos, peneira estática, tanque de acidificação e equalização, reator anaeróbio compartimentado, reator de manta de lodo (UASB) e decantador, alcançaram uma eficiência média $70,28 \%$ na remoção de óleos e graxas. Reinaldo et al. (2012), ao avaliarem o desempenho de sistema decantodigestor com filtro biológico seguido por alagado construído e reator solar no tratamento de esgoto doméstico, obtiveram remoções de óleos e graxas variando de 95 a 99,7\%, ao longo do período experimental. Batista et al. (2008), ao analisarem a remoção de óleos e graxas durante a filtração de ARS em peneiras estáticas inclinadas, passando primeiramente em caixa de gordura, obtiveram remoção de $11 \%$ em peneira de $47 \mu \mathrm{m}$.

Além da remoção pelo processo físico de filtração, a elevada eficiência de remoção de óleos e graxas, obtida quando utilizado o bagaço de cana-de-açúcar como material filtrante, pode ser atribuída, também, à elevada capacidade de adsorção e absorção desse material.
Segundo Rubio et al. (2003), sorventes em geral atuam por meio de dois mecanismos, adsorção e absorção. Na absorção, o acúmulo de óleo ocorre por meio da capilaridade ou sucção capilar. Já a adsorção está baseada na área superficial específica do adsorvente e na interação hidrofóbica entre o adsorvente e o adsorvato. Em muitos casos, a sorção de hidrocarbonetos apolares ocorre por meio de uma combinação desses mecanismos. Entretanto, no caso da sorção de óleos, depois que os capilares estão cheios, o óleo adicional deve ser capaz de se adsorver no material por interação com o óleo já sorvido. Dessa forma, acredita-se que, no caso da adsorção, o óleo adere à interface do bagaço devido à sua estrutura hidrofóbica e por absorção do óleo no interior dos poros vazios do bagaço de cana-de-açúcar, por capilaridade. De acordo com Schneider e Rubio (2003), este fenômeno é conhecido como interpenetração na fase sólida, processo decorrente da alta porosidade do material.

Mesmo tendo a serragem de madeira apresentado maior porosidade (Quadro 1), fato também constatado em análise feita por Brandão et al. (2003), foi o bagaço de cana-de-açúcar picado que proporcionou maior remoção de óleos e graxas (Quadro 3). Isto pode ser devido ao fato do bagaço de cana-de-açúcar apresentar maior tensão interfacial com óleos e graxas da ARS e a maior molhabilidade desse material filtrante com essas substâncias, sendo, assim, as 
principais razões para explicar a maior eficiência desses materiais filtrantes. Santos et al. (2007) também observaram elevada capacidade de adsorção de hidrocarbonetos leves pelo bagaço de cana-de-açúcar. Os autores avaliaram o uso de diferentes biomassas, tais como o sabugo de milho, mesocarpo do coco, serragem de madeira e bagaço de cana-de-açúcar como adsorventes de hidrocarbonetos leves e observaram que o mesocarpo do coco apresentou maior capacidade de adsorção, seguido do bagaço de cana-de-açúcar e, por último, a serragem de madeira, com valores muito semelhantes aos obtidos quando utilizaram o sabugo de milho.

Além do elevado poder de adsorção, o bagaço de cana-de-açúcar apresenta uma superfície mais filamentosa em relação aos outros materiais, o que proporciona maior eficiência de retenção no espaço entre os filamentos. Ademais, possui maior superfície específica que os outros materiais, tal como constatado por Brandão et al. (2003), ao analisarem as características físicas e químicas de diferentes materiais filtrantes, como o bagaço de cana-de-açúcar, a serragem de madeira, o sabugo de milho, fino de carvão vegetal, casca de frutos do cafeeiro e casca de arroz.

A elevada remoção de óleos e graxas obtida pelos materiais filtrantes é um aspecto altamente positivo para o meio ambiente, pois além de ser um sistema de filtração de baixo custo de implantação e de operação, já que são aproveitados os resíduos orgânicos, subprodutos de atividades agropecuárias e agroindustriais, trata os resíduos gerados numa atividade potencialmente causadora de degradação ambiental.

Apesar da eficiente remoção, os filtros avaliados não foram capazes de proporcionar concentração de óleos e graxas no efluente que atendesse a Resolução CONAMA $\mathrm{N}^{\mathrm{o}} 430 / 2011$, na qual estão estabelecidos padrões de lançamento de efluentes em corpos hídricos, já que a concentração de óleos vegetais e gorduras animais deve ser inferior a $50 \mathrm{mg} \mathrm{\textrm {L } ^ { - 1 }}$. Mesmo não atendendo a supracitada Resolução, indubitavelmente o uso de filtro orgânico permitiu melhoria considerável na qualidade do efluente, o que facilita enormemente as etapas subsequentes do tratamento ou a disposição final da ARS no solo.
Considerando que o uso de filtros constitui tratamento primário da ARS, outras etapas de tratamento devem ser incluídas, com as quais se pode, com relativa facilidade, adequar o efluente aos padrões de lançamento. Há de se considerar, também, que para adequação da ARS para a aplicação por sistemas localizados (microaspersão e gotejamento) não tem sido verificada restrição quanto ao uso do efluente com concentrações de óleos e graxas até superiores às encontradas nos efluentes dos filtros orgânicos avaliados neste trabalho.

\section{CONCLUSÃO}

- Os filtros orgânicos de bagaço de cana-de-açúcar triturado, serragem de madeira e pergaminho de grãos de café proporcionaram elevada remoção de óleos e graxas da ARS, tendo sido obtidos valores de $97,2 \% ; 88,9 \%$ e $82,3 \%$, respectivamente. Entretanto, ainda assim, não foram eficientes o suficiente para atender a Resolução CONAMA No 430/2011, no que se refere ao padrão de lançamento do efluente em corpos hídricos para óleos e graxas.

\section{REFERÊNCIAS BIBLIOGRÁFICAS}

APHA - AMERICAN PUBLIC HEALTH ASSOCIATION; AWWA - AMERICAN WATER WORKS ASSOCIATION; WEF - WATER ENVIRONMENT FEDERATION. Standard methods for the examination of water and wastewater. 21. ed. Washington: APHA/AWWA/ WEF, 2005. 1268p.

BATISTA, R.O.; OLIVEIRA, R.A.; CECON, P.R.; SOUZA, J.A.R.; BATISTA, R.O. Filtração de água residuária de suinocultura em peneiras estacionárias inclinadas. Engenharia na Agricultura, Viçosa, MG, v.16, n.4, p.465-470 Out./Dez., 2008.

BERTI, A.P.; DÜSMAN, E.; SOARES, L.C.; GRASSI, L.E.A. Efeitos da contaminação do ambiente aquático por óleos e agrotóxicos. SaBios: Rev. Saúde e Biol., v.4, n.1, p.45- 51, jan.jun. 2009.

BRANDÃO, V.S.; MATOS, A.T.; FONTES, M.P.F.; MARTINEZ, M.A. Retenção de poluentes 
em filtros orgânicos operando com águas residuárias da suinocultura. Revista Brasileira de Engenharia Agrícola e Ambiental, Campina Grande, v.7, n.2, p.329-334, 2003.

LO MONACO, P.A.; MATOS, A.T.; JORDÃO, C.P.; CECON, P.C.; MARTINEZ, M.A. Influência da granulometria da serragem de madeira como material filtrante no tratamento de águas residuárias. Revista Brasileira de Engenharia Agrícola e Ambiental, Campina Grande, v.8, n.1, p.116-119, 2004.

LO MONACO, P.A.V.; MATOS, A.T; SARMENTO, A.P.; LOPES JÚNIOR, A.V.; LIMA, J.T. Desempenho de filtros constituídos por fibras de coco no tratamento de águas residuárias de suinocultura. Engenharia na Agricultura, Viçosa, v.17, n.6, p.473-480, 2009.

LO MONACO, P.A.V.; MATOS,A.T.; BRANDÃO, V.S. Influência da granulometria dos sólidos triturados de sabugo de milho e bagaço de canade-açúcar como materiais filtrantes no tratamento de águas residuárias da suinocultura. Engenharia Agrícola, Jaboticabal, v.31, n.5, p.975-985, 2011 a.

LO MONACO, P.A.V.; MATOS, A.T.; EUSTÁQUIO JÚNIOR, V.; SARMENTO, A.P.; MOREIRA, R.M.G. Desempenho de filtros constituídos por pergaminho de grãos de café (Coffeasp.) no tratamento de águas residuárias. Coffe Science, Lavras, v.6, n.2, p.120-127, 2011 b.

MAGALHÃES, M.A.; MATOS, A.T.; DENÍCULI, W. AZEVEDO, R.F. Influência da compressão no desempenho de filtros orgânicos para tratamento de águas residuárias da suinocultura. Engenharia na Agricultura, v.13, n.1, p.26-32, jan./mar. 2005.

MAGALHÃES, M.A.; MATOS, A.T.; DENÍCULI, W.; TINOCO, I.F.F. Operação de filtros orgânicos utilizados no tratamento de águas residuárias da suinocultura. Revista Brasileira de Engenharia Agrícola e Ambiental, Campina Grande, v.10, n.2, p.472-478, 2006.

MATOS, A.T.; MAGALHÃES, M.A.; FUKUNAGA, D. Remoção de sólidos em suspensão na água residuária da despolpa de frutos do cafeeiro em filtros constituídos por pergaminho de grãos de café submetido a compressões. Engenharia Agrícola, Jaboticabal, v.26, n.2, p.610-616, 2006.

MATOS, A.T.; MAGALHÃES, M.A; SARMENTO, A.P. Perda de carga em filtros orgânicos utilizados no tratamento de água residuária de suinocultura. Engenharia Agrícola, Jaboticabal, v.30, n.3, p.527-537, 2010.

PEREIRA, E.L.CAMPOS, C.M.M.; MOTERANI, F.; OLIVEIRA NETO, A.M. Eficiência de um sistema de reatores anaeróbios no tratamento de efluentes líquidos de suinocultura. Acta Scientiarum. Technology, Maringá, v.33, n.3, p.287-293, 2011.

REINALDO, G.P.B.; BATISTA, R.O.; SILVA, P.C.M.; LEMOS FILHO, L.C.A.; FERREIRA NETO, M.; SANTOS, D.B. Desempenho de sistema decanto-digestor com filtro biológico seguido por alagado construído e reator solar no tratamento de esgoto doméstico. Ambi-Agua, Taubaté, v.7, n.2, p.62-74, 2012.

RESOLUÇÃO CONAMA No 430/2011. "Dispõe sobre condições e padrões de lançamento de efluentes, complementa e altera a Resolução № 357, de 17 de março de 2005, do Conselho Nacional do Meio Ambiente - CONAMA." Data da legislação: 13/05/2011 - Publicação DOU $\mathrm{n}^{\circ}$ 92, de 16/05/2011, pág. 89. Disponível em: $<$ http://www.mma.gov.br/port/conama/legiabre. cfm?codlegi=646>. Acesso em: $25 \mathrm{fev} .2013$.

RUBIO, J; RIBEIRO, T.H.; SMITH, R.W.A Dryed Hydrophobic Aquaphyte as na Oil Filter for Oil/ Water Emulsions. Spill Science \& Technology Bulletin, v.8, p.483-489, 2003.

SANTOS, E.G.; ALSINA, O.L.S.; SILVA, F.L.H. Desempenho de biomassas na adsorção de hidrocarbonetos leves em efluentes aquosos. Química Nova, São Paulo, v.30, n.2, p.327-331, 2007.

SCHMIDT, C.A.B. Remediação in situ de solos e águas subterrâneas contaminados por líquidos 
orgânicos não miscíveis em água (NAPLs), Série Temática: Resíduos Sólidos e Geotecnia Ambiental, v.1, Rio de Janeiro: COAMB/FEN/ UERJ, 2010. 62 p.

SCHNEIDER, I.A.H.; RUBIO, J. Plantas Aquáticas: Adsorventes Naturais para a Melhoria da Qualidade das Águas. XIX Prêmio Jovem Cientista, 2003. Água: Fonte de Vida. UFRGS, 2003.

SILVA, V.L.M.M; GOMES, W.C.; ALSINA, O.L.S.
Utilização do bagaço de cana de açúcar como biomassa adsorvente na adsorção de poluentes orgânicos. Revista Eletrônica de Materiais e Processos, Campina Grande, v.2, n.1, p.27-32, 2007.

SOUZA, R.S.; LIMA, L.M.R.; SILVA, V.L.M.M. Adsorção de óleo diesel em sistema de leito diferencial com biomassa bagaço de cana-deaçúcar. Revista Eletrônica de Materiais e Processos, Campina Grande, v.6, n.2, p.123-126, 2011. 